\title{
Novel treatment of pulmonary embolism in a patient with sickle cell disease
}

\author{
Marium Husain ${ }^{1}$, Payal Desai ${ }^{2 *}$, Peter Bittenbender ${ }^{3}$, Eric Kraut ${ }^{2}$ and Raymond Magorien ${ }^{4}$ \\ ${ }^{1}$ Division of Hospital Medicine, The Ohio State University Wexner Medical Center, Columbus, Ohio, USA \\ ${ }^{2}$ Division of Hematology, The Ohio State University Wexner Medical Center, Columbus, Ohio, USA \\ ${ }^{3}$ Summa Health System, Division of Interventional Cardiology, Akron, Ohio, USA \\ ${ }^{4}$ Division of Cardiology, The Ohio State University Wexner Medical Center, Columbus, Ohio, USA
}

\begin{abstract}
Patients with sickle cell disease (SCD) have an increased prevalence of venous thromboembolism (VTE) and conversely, are also at risk for hemorrhagic complications. This poses a unique situation when these patients present with pulmonary embolism (PE) and require thrombolytics. The use of ultrasound-guided thrombolytic therapy did not increase bleeding complications when administered to a patient with SCD with prior history of hemorrhagic stroke. This is a novel treatment for PE in patients with high-risk for bleeding complications. We believe that our findings are a significant contribution to the treatment of PE in SCD.
\end{abstract}

\section{Introduction}

Patients with Sickle cell disease are at an increased risk for venous thromboembolism (VTE). However, they are also at high risk for bleeding complications as well. We discuss a particularly challenging case of treating VTE with a history of hemorrhagic stroke.

\section{Case report}

A 29-year old African-American male with a history of sickle cell disease (sickle beta plus thalassemia), hemorrhagic stroke, and acute chest syndrome presented with acute chest pain that was typical for his usual vaso-occlusive crisis. He was oxygenating well on room air and did not have an infiltrate on his chest $\mathrm{x}$-ray. The patient was treated with pain medications and gentle hydration.

However, on Day 2 of hospitalization, he developed acute tachycardia, respiratory distress, and hypoxia to $70 \%$ on room air. Although VOC could cause symptoms of chest pain and tachycardia, the patient's symptoms were not completely consistent with this disease process.

A Computed Tomography (CT) angiogram was immediately obtained and revealed multiple bilateral pulmonary emboli with right ventricular (RV) enlargement, as seen in Figure 1. Bilateral upper and lower extremity dopplers were negative for deep vein thromboses.

This patient was classified as having submassive pulmonary embolism (PE). Although he was in respiratory distress and showing signs of right heart strain, his blood pressures had remained stable.

The patient was intubated for airway protection. Given the bleeding risk, ongoing clinical compromise, large central bilateral clot burden, and enlarged right ventricle, an alternative to standard heparin therapy was entertained (Figure 1).

The decision was made to pursue thrombolytics. The patient underwent ultrasound-assisted catheter-directed thrombolysis (USAT) using an EKOS catheter with a low dose tPA infusion $(1 \mathrm{mg} / \mathrm{hr}$ for 12 hours, total $24 \mathrm{mg}$ ). Figure 2 shows imaging of the EKOS catheters in our patient (Figure 2).

The patient's symptoms dramatically improved and had no bleeding complications. The patient's pulmonary artery pressures improved and he required no supplemental oxygen therapy at discharge. He was successfully transitioned from a heparin drip to Coumadin.

\section{Discussion}

The patient presented with acute chest pain, and although acute

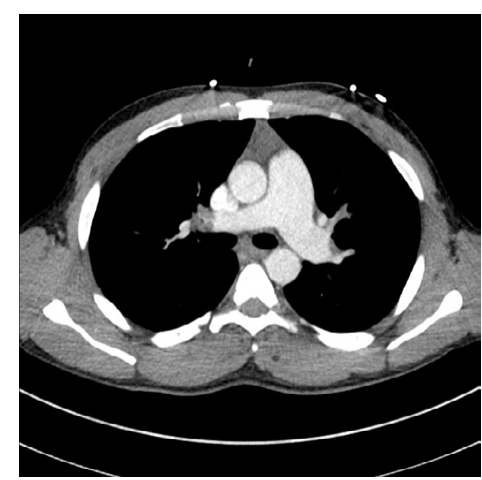

Figure 1. CT showing bilateral PE.

Correspondence to: Payal Desai, Assistant Professor, Director of the Ohio State Adult Sickle Cell Program Division of Hematology, The Ohio State University Wexner Medical Center, Columbus, Ohio, USA, Tel: (614)293-2887; Fax: (614)293-7526; E-mail: Payal.Desai@osumc.edu

Key words: embolism and thrombosis, heparin, pulmonary veno-occlusive diseasel, sickle cell disease, thrombolytic therapy

Received: February 17, 2017; Accepted: March 01, 2017; Published: March 03, 2017 


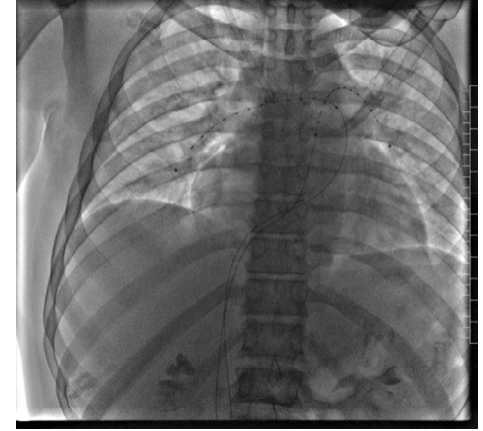

Figure 2. EKOS catheters in our patient.

VOC was an initial assumption given his normal vitals and normal chest $\mathrm{x}$-ray, after quick clinical deterioration, he was found to have acute submassive PE. Patients with SCD are at risk for developing venous clots and venous thromboembolism (VTE). While common risk factors for VTE are frequent hospitalizations, high-risk surgeries, central venous catheters, and pregnancy, further research reveals SCDspecific risk factors: thrombophilic defects, genotype and splenectomy [1-3]. These RBC membrane defects contribute to an environment that is prone to thrombophilia. Thrombi develop in situ from small vessel obstruction as a result of sickling of hemolyzed RBCs or VTE from a deep vein clot. There are coagulation parameter alterations that exist, such as development of anti-phospholipid antibodies, which are considered to be secondary to changes in the hemolyzed RBCs membranes [1]. In addition, there are also low protein $\mathrm{C}$ and $\mathrm{S}$ levels, as well as increased tissue factor expression and elevated von Willebrand factor (vWF) levels, which contribute to thrombophilia [1,4]. Other studies have shown that the presence of SC and Sbeta-plus thalassemia genotypes are at increased risk of non-catheter related VTE, possibly as a result of increased whole blood viscosity [3]. Studies have found an increased risk of PE in SCD patients, and also at a younger age of incidence [3]. Patients with SCD are found to have PE at an average of 28-30 years in SCD patients compared to age 57 in controls [5].

Our patient was suffering from a submassive PE. A massive PE would have presented with hemodynamic instability, manifested by hypotension, right heart strain, and cardiogenic shock [6]. It can result in significant morbidity and mortality without intervention [7]. Currently, the standard of care for a massive PE is systemic tPA [8]. Per the International Cooperative Pulmonary Embolism Registry, systemic thrombolytics carry a $77 \%$ success rate, but also a $22 \%$ complication risk, including major hemorrhage [9]. Patients with sickle cell disease are at risk of hemorrhagic complications, given a higher incidence of small vessel disease. This was a particular concern for our patient with a history of prior central nervous system disease at a young age.

Given this significant concern for hemorrhagic complications, USAT offers a novel alternative for patients with SCD and massive or submassive pulmonary embolism. The main principle is accessing the clot with a catheter and using high-frequency, low-power ultrasound to separate fibrin strands in order to enhance the penetration of thrombolytics [10]. In contrast to conventional systemic thrombolytics, USAT with low dose TPA infusion has the same bleeding risk as heparin therapy. In addition, USAT is performed in a catheterization lab. The ULTIMA trial found that in those patients at intermediate risk of death from a PE, USAT instituted in the catheterization lab does not augment bleeding risk and is associated with early enhanced RV function compared to standard heparin therapy. The rate of bleeding complication with USAT was $2.4 \%$, compared to $11.5 \%$ when using heparin alone.
While further studies need to be performed to confirm both safety and efficacy in a SCD patient population, this offers a novel therapeutic option for a patient population that is at high risk of hemorrhagic complications and also thrombotic complications. Further studies are being performed: currently, the clinical trial (NCT01513759) studying a low-dose USAT protocol is completed, with final results still pending.

\section{Authorship and contributorship}

Husain M: Co-author and performed literature review.

Desai P: Co-author, performed literature review, provided expert background on sickle cell disease.

Bittenbender P: Edited article, provided images and technical background to the paper.

Kraut E: Edited article, and provided expert background on sickle cell disease.

Magorien R: Edited article, provided images and technical background to the paper.

\section{Conflicts of interest}

The authors declare that there is no conflict of interest regarding the publication of this paper.

\section{References}

1. Naik RP, Streiff MB, Lanzkron S (2013) Sickle cell disease and venous thromboembolism: what the anticoagulation expert needs to know. $J$ Thromb Thrombolysis 35: 352-358. [Crossref]

2. Kearon C, Kahn SR, Agnelli G, Goldhaber S, Raskob GE, et al. (2008) Antithrombotic therapy for venous thromboembolic disease: American College of Chest Physicians Evidence-Based Clinical Practice Guidelines (8th Edition). Chest 133: 454S-545S [Crossref]

3. Naik RP, Streiff MB, Haywood C Jr, Nelson JA, Lanzkron S (2013) Venous thromboembolism in adults with sickle cell disease: a serious and under-recognized complication. Am J Med 126: 443-449. [Crossref]

4. Kaul DK, Nagel RL, Chen D, Tsai HM (1993) Sickle erythrocyte-endothelial interactions in microcirculation: the role of von Willebrand factor and implications for vasoocclusion. Blood 81: 2429-2438

5. Stein PD, Beemath A, Meyers FA, Skaf E, Olson RE (2006) Deep venous thrombosis and pulmonary embolism in hospitalized patients with sickle cell disease. Am J Med 119: 897. [Crossref]

6. Goldhaber SZ, Visani L, De Rosa M (1999) Acute pulmonary embolism: clinical outcomes in the International Cooperative Pulmonary Embolism Registry (ICOPER) Lancet 353: 1386-1389.

7. Buller HR, Agnelli G, Hull RD, Hyers TM, Prins MH, et al. (2004) Antithrombotic therapy for venous thromboembolic disease: the Seventh ACCP Conference on Antithrombotic and Thrombolytic Therapy. Chest 126: 401S-428S.

8. Ohene-Frempong K, Weiner SJ, Sleeper LA, Miller ST, Embury S, et al. (1998) Cerebrovascular accidents in sickle cell disease: rates and risk factors. Blood 91: 288294. [Crossref]

9. Heit JA, Cohen AT, Anderson FA (2005) Estimated annual number of incident and recurrent, non-fatal and fatal venous thromboembolism (VTE) events in the U.S. Blood 106: 910 .

10. Kucher N, Boekstegers P, Muller OJ, Kupatt C, Beyer-Westendorf J, et al. (2014) Randomized, Controlled Trial of Ultrasound-Assisted Catheter-Directed Thrombolysis for Acute Intermediate-Risk Pulmonary Embolism. Circulation 129: 479-486.

Copyright: (C)2017 Husain M. This is an open-access article distributed under the terms of the Creative Commons Attribution License, which permits unrestricted use, distribution, and reproduction in any medium, provided the original author and source are credited. 